\title{
Moisture, Anisotropy, Stress State, and Strain Rate Effects on Bighorn Sheep Horn Keratin Mechanical Properties
}

\author{
K.L. Johnson, ${ }^{1,2}$ M.W. Trim, ${ }^{3}$ D.K. Francis, ${ }^{2}$ W.R. Whittington, ${ }^{2}$ J.A. Miller, ${ }^{2}$ C.E. Bennett, ${ }^{2,4}$ \\ and M.F. Horstemeyer ${ }^{1,2}$ \\ ${ }^{1}$ Department of Mechanical Engineering, Mississippi State University, Mississippi State, MS 39762, USA \\ ${ }^{2}$ Center for Advanced Vehicular Systems (CAVS), 200 Research Blvd, Mississippi State, MS 39762, USA \\ ${ }^{3}$ US Army Engineer Research and Development Center, Geotechnical and Structures Laboratory, 3909 Halls Ferry \\ Rd, Vicksburg, MS 39180 \\ ${ }^{4}$ Department of Agricultural and Biological Engineering, Mississippi State University, Mississippi State, MS 39762, \\ USA
}

\begin{abstract}
This paper investigates the effects of moisture, anisotropy, stress state, and strain rate on the mechanical properties of the bighorn sheep (Ovis Canadensis) horn keratin. The horns consist of fibrous keratin tubules extending along the length of the horn and are contained within an amorphous keratin matrix. Samples were tested in the rehydrated (35 wt.\% water) and ambient dry (10 wt.\% water) conditions along the longitudinal and radial directions under tension and compression. Increased moisture content was found to increase ductility and decrease strength, as well as alter the stress state dependent nature of the material. The horn keratin demonstrates a significant strain rate dependence in both tension and compression, and also showed increased energy absorption in the hydrated condition at high strain rates when compared to quasi-static data, with increases of $114 \%$ in tension and $192 \%$ in compression. Compressive failure occurred by lamellar buckling in the longitudinal orientation followed by shear delamination. Tensile failure in the longitudinal orientation occurred by lamellar delamination combined with tubule pullout and fracture. The structure-property relationships quantified here for bighorn sheep horn keratin can be used to help validate finite element simulations of ram's impacting each other as well as being useful for other analysis regarding horn keratin on other animals.
\end{abstract}

Keywords: Sheep Horn; Keratin; Stress state dependence; Strain rate dependence, Mechanical properties, Structure-property relations

\section{Introduction}

Male bighorn sheep engage in fights when they move to seasonal home ranges and encounter strangers [1] or when challenging tending rams for mating access to defended estrous ewes [2]. During these fights, the rams' horns clash together at high speeds (up to $5.5 \mathrm{~m} / \mathrm{s}$ ), resulting in forces up to $3400 \mathrm{~N}$ [3]. By protecting the ram's head during the fight, the horns' function is vital to the safety of the ram. Considering the average bighorn sheep lifespan of 13 years [4] and their important role in mating and territory control, the horns must be energy absorbent and very resistant to fracture. Due to the safety aspect of these horns, along with their superior durability and performance, the horn material is poised as a great material to study with regards to natural safety and impact resistant structures. 
The horns of bighorn sheep consist of a core of cancellous bone covered with a germinative epithelium that generates new cell growth, all of which is surrounded by a sheath composed of $\alpha$ keratin $[5,6] . \alpha$-Keratin is a structural protein found in horns, hooves, hair, claws, and wool. The second type of keratin is known as $\beta$-keratin, which is tougher than $\alpha$-Keratin [7]. While the $\alpha$ Keratin molecular unit is a coiled-coil heterodimer, $\beta$-keratin consists of pleated sheets [8]. $\beta$ keratin is found in avian feathers and beaks, and reptilian scales and claws [7,9]. The $\alpha$-keratin sheath of the bighorn sheep is anisotropic about the radial direction, which is defined as the direction normal to the long axis of the horn (longitudinal) and oriented towards the centerline of the horn [10]. The keratin sheath is a composite-like structure consisting of long, hollow keratin fiber tubules in an amorphous keratin matrix. The chemical bonding between the fibers and the matrix is accomplished by sulfur cross links [11]. This complete protein composition is different than most biological materials such as bone, tooth, and nacre, which normally include a mineral component for added stiffness [12-14]. The tubules in bighorn sheep keratin typically form an elliptical shape with major and minor axes dimensions of 93 and $29.6 \mu \mathrm{m}$, respectively [15]. The tubules extend along the length of the horn in the growth direction, called the longitudinal direction, and are randomly dispersed between keratin lamellae. These lamellae are stacked in the radial direction and measure between 2 and $5 \mu \mathrm{m}$ in thickness [15]. Equine hooves, bovine hooves, and Rhinoceros horns also share this keratin-based tubule structure [5]. Being that keratin poses a structural anisotropic makeup, and has wider natural uses in other animals, understanding the anisotropic behavior of this material is paramount in relating the behavior to the complex morphology of the animal parts in which keratin find usage.

Keratinous materials are also highly affected by moisture content. In these materials, the strength and stiffness are greater at lower moisture contents, yet more brittle. Bonser [16] tested ostrich claw keratin at 11.58 and $28.79 \%$ water by mass and showed decreased stiffness and hardness. Many studies also show that with increasing moisture content, strain to failure in keratin increases at the expense of strength and stiffness [5,13,15,17-19]. In several studies, these keratinous materials were found to have the highest work of fracture at intermediate moisture contents that reflect values found in vivo [18,20]. At these intermediate moisture levels, water acts as a plasticizer and leads to increased toughness. Bertram and Gosline [20] found that dehydration affects the matrix much more than the microfibrils. They suggested that intermediate hydration allows an intermediate degree of secondary cross linking (hydrogen bonding between the polymers of the matrix phase), increasing stiffness while still allowing extensibility. Based on this extensive knowledge of moisture content effects on overall plasticity, moisture content should also be investigated with regards to strain rate and stress state to elucidate any effects on these properties as well. Wang et al. provides a thorough review of keratin and its properties in different biological systems [8].

The keratin found in bighorn sheep has been well researched at quasi-static strain rates, but the only high rate data that exists in the literature is compression in the dry condition $[4,5,15]$. The Split-Hopkinson Pressure Bar (SHPB) offers a way to examine materials at higher strain rates [21,22]. As discussed previously, the sheep's horn is designed for impacts up to $5.5 \mathrm{~m} / \mathrm{s}$. By performing SHPB experiments, data in this study can combined with existing quasi-static experimental data to bound the entire operating range of the horn and thereby reveal any unique strain rate dependent properties that might otherwise be missing from lower strain rate experiments alone.

Hopkinson [21] originally designed the experiment to use a metal bar to measure the pressure pulse propagation. The method was later altered by Kolsky [22] to use two bars to 
measure stress and strain. The technique places a specimen between two straight bars, called the incident bar and the transmitted bar. A pressure wave, either compressive or tensile, is introduced in the incident bar at the end opposite the specimen. The wave, called the incident wave, travels to the end of the incident bar in contact with the specimen, at which point a portion of the wave is reflected, called the reflected wave, and the remainder, called the transmitted wave, enters the specimen causing deformation. After leaving the specimen, the wave travels down the transmitted bar. Strain gages on the incident and transmitted bars capture the strain responses. Using the bar material properties and amplitudes of the three waves, the stress response of the specimen can then be calculated.

Based on the aforementioned pertinence of studying the effects of moisture, anisotropy, stress state, and strain rate on the mechanical properties of bighorn sheep horn keratin, this study makes the first attempt at garnering and analyzing the relationship between all of these quantities. Microstructural analysis is also utilized to offer structure-based hypotheses for the property relationships observed. Using this SHPB technique, our study examines the response of the horn keratin of bighorn sheep under high strain rate loading, which has scarcely been performed for this material. Finally, the effects of moisture on the strain rate, stress state, and anisotropy will be analyzed to offer a global definition of the deformation space of bighorn sheep horn keratin. The results aid in understanding the energy absorption of the horns of the bighorn sheep during impacts, and the information garnered from this study can be used to greater inform material models. For example, the data presented here is currently being used to simulate bighorn sheep impacts with the goal of understanding how the horns protect the ram brain from impacts. Any relevant mechanisms that can be discovered can be utilized in protective equipment for human heads.

\section{Materials and Methods}

Two bighorn sheep (Ovis Canadensis) horn sheaths, approximately $1 \mathrm{~m}$ in longitudinal length and $12 \mathrm{~cm}$ in diameter at the base, were donated by the Montana Department of Fish, Wildlife, and Parks. The animals were killed for reasons unrelated to this study. The specimens were stored in a controlled environment with a temperature of $-18^{\circ} \mathrm{C}$ and a relative humidity of 30 percent until needed. The exact amount of time that elapsed between the harvesting of the horns and testing was indeterminable. High strain rate tension and compression tests were performed using a split-Hopkinson pressure bar apparatus with the incident and transmitter bars consisting of a 7075 aluminum alloy. Testing was performed at an average strain rate of $1000 \mathrm{~s}^{-1}$.

Two sets of specimens were used for high rate tensile and compression testing. The dog bone tensile specimens had a gage length of $4.5 \mathrm{~mm}$, a gage width of $2 \mathrm{~mm}$, and a gage thickness of 2 $\mathrm{mm}$. The cylindrical compression specimens had a length of $6.35 \mathrm{~mm}$ and a diameter of 12.7 $\mathrm{mm}$. Sections of horn were cut and sanded to the desired thickness, then cut to the appropriate profile using a water-jet cutting machine to insure a smooth surface with no heat affected zone. Twelve tensile specimens were prepared, with six cut in the longitudinal direction and six in the radial direction. Of the six for each orientation, three were tested in the hydrated condition, and three were tested in the ambient dry condition. Forty-eight compression specimens were prepared to be tested, twenty-four in the longitudinal direction and twenty-four in the radial direction. Of the twenty-four for each orientation, twelve were tested in the ambient dry condition and twelve were tested in the hydrated condition. Figure 1 illustrates the hierarchical structure of the horn and the orientation of the longitudinal and radial test specimens. In order to determine the effects of horn moisture content under high rate loading, the specimens to be tested 
in the hydrated condition were immersed in deionized water for three days to allow for complete saturation [23]. This process has been shown to produce a moisture content of $35 \mathrm{wt} \%$ water [15]. The ambient dry keratin possessed a moisture content of $10 \mathrm{wt} . \%$ water. After mechanical testing, two-tailed T-tests were performed in order to confirm statistical significance of the changes in strength caused by moisture addition and orientation under both compressive and tensile high strain rate loading. A p-value of 0.05 was chosen for the statistical comparison. A pvalue of 0.05 indicates that for each t-test, if $\mathrm{P}\left(\mathrm{t}_{\text {stat }} \leq \mathrm{t}_{\text {crit }}\right)$ is less than 0.05 , the difference in the mean strength values does not lie with a $95 \%$ confidence interval, and there is a statistically significant difference in strength. In the probability equation, $t_{\text {stat }}$ is the $t$ statistic calculated for the two populations (wet and dry, for example) using the mean, sample variance, and sample size, and $t_{\text {crit }}$ is the $t$ statistic that represents the bounds of the $95 \%$ confidence interval.

Strain rate effects were investigated by comparing the high rate data obtained in this study with quasi-static data previously published in [15]. After failure of the tensile specimens, the fracture surfaces were imaged using scanning electron microscopy (SEM) using a Zeiss SUPRA 40 Field Emission Gun SEM in secondary electron (SE) mode at 5kV. Prior to imaging, the samples were allowed to dry at ambient conditions and were given a $12.5 \mathrm{~nm} \mathrm{Ag} / \mathrm{Pd}$ coating in a sputter coater (Polaron SC7640, Quorum Technologies Ltd., CT, USA).

\section{Results and Discussion}

\subsection{Moisture Effects}

Figure 2 shows the effects of moisture and anisotropy during high rate compressive loading. A clear transition from brittle-to-ductile behavior can be observed as the water content increased for both orientations; as the water increased the failure strain increased also. This brittle-toductile transition also incurred a stress reduction for both the longitudinal and radial orientations. Hence, the mechanical behavior shown in Figure 2 demonstrates that higher moisture content greatly reduces compressive strength and increases failure strain. To confirm that moisture produces a change in mechanical behavior, a two-tailed T-test was performed on each orientation to compare the dry and wet results. The comparison of average compressive strength for the dry and wet longitudinal orientations resulted in a $\mathrm{P}$-value of $7 \times 10^{-6}$. The comparison of average compressive strength for the dry and wet radial orientations resulted in a P-value of $5 \times 10^{-4}$. Both tests showed that there is a significant difference in compressive strength after the addition of moisture. The results of the T-tests as well as the difference in strength caused by moisture addition is shown in Table 1. The fracture mechanisms in compression were consistent with previously reported quasi-static testing $[5,15]$ in that tubule collapse and buckling of lamellar layers followed by delamination were observed.

During high rate tensile deformation (Figure 3), the stress reduction due to increased water content occurred in both orientations, but was much less significant in the radial direction. A two-tailed T-test was again performed on each orientation to compare the dry and wet results. The comparison of average tensile strength for the dry and wet longitudinal orientations resulted in a P-value of 0.03 . The comparison of average tensile strength for the dry and wet radial orientations resulted in a P-value of 0.003 . Both of these results indicate a statistical difference in tensile strength caused by moisture addition. The results of the T-tests as well as the difference in strength caused by moisture addition is shown in Table 2. The dry longitudinal condition possessed a significant ultimate strength of $117 \mathrm{MPa}$, which is greater than many thermoplastics such as polycarbonate and even higher than some fiber-reinforced polymer composites [24]. 
However, the failure strain was very low in the dry longitudinal condition. Keratin tubules were exposed on the fracture surfaces and are shown in Figure 4(b), circled in white. A scaled view of the complete fracture surface of a dry longitudinal high rate tension specimen is shown in Figure 4(a). The wavy lamellar layers that make up the keratin matrix can also be seen. Failure initiated at the bottom of the image and followed a typical Mode 1 crack path that traveled approximately $80 \%$ across the gage section. The failure mechanism then changed when the lamellar structure delaminated parallel to the loading axis, before continuing Mode 1 failure higher up the gauge section. This delaminated surface is visible in the top half of Figure 4(a). With the addition of moisture, the longitudinal orientation exhibited tensile failure strains up to $70 \%$, while the wet radial condition exhibited a failure strain less than $15 \%$; hence, the anisotropy changed $78 \%$ due to water. The fracture surface of the wet longitudinal high rate tension specimens indicated a different failure mechanism when compared to the dry condition (Figure 5(a-c)). The combined Mode 1-delamination failure was again observed for the wet condition, but the wet condition revealed a much greater degree of fiber pullout. Figure 5(b) shows the fiber pullouts as the frayed fibers are the fractured tubules. The material also showed the standard ductile cup-andcone type failure illustrated in Figure 5(c). This ductility was not observed in the dry condition.

When loaded in the radial direction, the weaker amorphous keratin matrix carried the majority of the load, causing delamination of the tubules and lamellar layers. The failure surface of the dry radial condition, found in Figure 6(a), clearly shows channels left by tubule pullout. A partially delaminated tubule circled in white is illustrated. The fracture surface of the dry radial keratin also possessed a flaky appearance, shown in Figure 6(b), due to the primary loading of the keratin matrix. Although the increased moisture content does not significantly reduce the radial strength, ductility increased by an order of magnitude. The fracture surface morphology in Figure 7 reveals the increased plasticity in the amorphous keratin matrix. Figure 7(a) also highlights a very distinct channel left by a delaminated keratin tubule. The channel diameter in Figure 7(b) is $56 \mu \mathrm{m}$, which is in the range for tubule diameters [15].

When compared to quasi-static mechanical properties, high strain rates resulted in a greater flow stress for both compressive and tensile loading in the hydrated condition, while maintaining a fairly large ductility. We note that greater strength and ductility lead to better energy absorption. This result is important, because ram impacts occur in nature at high rates, and the moisture content of their horns has been shown to contain approximately 20\% water [23], placing it between the bounds of the two conditions tested in our study. The $20 \%$ moisture content could possibly represent an optimized combination of strength and energy absorption. This has yet to be confirmed for horn keratin, but Bertram and Gosline [20] found that fracture toughness was maximal in horse hoof keratin at an intermediate moisture content (18.2\%). To further understand the behavior of horn keratin at intermediate moisture contents, the material could be tested after undergoing vapor phase absorption at different humidity levels.

\subsection{Anisotropy}

While the compressive strength in the longitudinal orientation appears slightly greater than the radial orientation for dry conditions, a two-tailed T-test resulted in a P-value of 0.65 , which demonstrates that there is not a conclusive difference in the average strength values. In wet conditions, there is a negligible change in compressive strength between fiber orientations. The greater compressive strength in the longitudinal dry condition could be due to the fibrous tubules resisting the lamellar buckling that occurs in compressive loading. 
The dry longitudinal tensile specimens withstood greater stresses than the radial tensile specimens due to the previously mentioned fibrous keratin tubules that run the length of the horn, causing the material to behave like a long fiber composite. The fibers, often referred to as intermediate filaments (IFs), comprise keratin molecules held together by hydrogen bonds and disulfide cross-links [25,26]. These strong bonds are responsible for holding the fibers together, which increase both stiffness and strength in the longitudinal direction. The disulfide bonds also provide insolubility in water [7]. Although both the tubules and matrix are made of keratin, the fibrous structure of the fibers compared to the amorphous matrix causes this strength increase. This effect is similar to recently created self-reinforcing thermoplastics. A common example is self-reinforcing polypropylene composites, such as Tegris ${ }$, Pure ${ }^{\circledR}$, and Curv $®$. Such materials can consist of spun fibers or extruded tapes woven into a fabric, then pressed into plates using pressure and heat. The resulting composite is typically much stronger than the parent material alone.

\subsection{Strain Rate Dependence}

Horn keratin demonstrates a clear dependence on strain rate in both tension and compression. To demonstrate this, quasi-static data [15] was combined with high rate testing results in Figure 8. The strain rate dependence occurs in both the longitudinal and radial orientations (Figures 8Figure 11), but appears to be more substantial in the longitudinal orientation shown in Figure 8 and Figure 9. The difference in rate values for the high strain rate testing are due to the nature of the SHPB test. For compressive testing, the rate is controlled by the air pressure applied to the striker bar. For tensile testing, the rate is controlled by the pre-strain applied to the incident bar. The behavior of biological materials also affects the final strain rate. As a result, difficulties arise when attempting to match strain rates between tests while maintaining a quality signal. However, these difficulties do not affect the accuracy of the results.

The largest increase in strength occurred in the dry longitudinal condition (Figure 8) during compressive loading, when the ultimate strength increased from $81 \mathrm{MPa}$ to $151 \mathrm{MPa}$ as the strain rate increased from $0.003 \mathrm{~s}^{-1}$ to $1300 \mathrm{~s}^{-1}$. The dry longitudinal compressive strength of $151 \mathrm{MPa}$ at $1300 \mathrm{~s}^{-1}$ well exceeds that of polycarbonate at $2000 \mathrm{~s}^{-1}$, which was shown to be $117 \mathrm{MPa}$ [27]. When the moisture content increased to $35 \%$, strain rate dependence decreased (Figure 9). In the radial orientation, the strain rate dependence became less pronounced (Figure 10 and Figure 11). One notable observation is that for the wet condition for both orientations, the strain rate dependence was greater in compression. For the dry condition, the strain rate dependence was greater in tension.

The demonstrated increase in stress at higher strain rates is very significant considering the function of the horn. As shown in Figure 9, the energy absorbed by the horn is much higher for both tension and compression at higher strain rates when compared to lower strain rates. At $45 \%$ strain, the keratin absorbed $114 \%$ more energy in tension and 192\% more energy in compression. Because greater energy is absorbed at larger strain rates, the animal is able to withstand greater violent impacts while resisting fracture and injury.

\subsection{Stress State Asymmetry}

Stress state asymmetry is an important material property to elucidate in keratin due to the material undergoing many deformation events involving both tension and compression. Based 
on the results in Figure 10, the mechanical behavior in the radial dry condition showed significant asymmetry. In this condition, tensile loading produced very similar results in both failure strength and strain for low and high strain rates, including lower strength and very low ductility. During compressive loading the stress-strain behavior differs greatly, particularly at the $0.003 \mathrm{~s}^{-1}$ strain rate, which exhibits an initial yield, plateau region, and subsequent densification. The change in mechanism could be due to the relatively weak interfacial strength between the lamellar layers and keratin tubules, which is exacerbated by tensile loading.

Moisture also presented an interesting effect on the stress state asymmetry in the longitudinal orientation, which is shown in Figure 12. Under high rate loading, the moisture content reversed the stress state that caused the highest yield strength. In dry conditions, compression caused the highest yield strength. In wet conditions, the highest yield strength came from tensile loading. This is the first time that the authors' are aware that moisture induces a yield stress asymmetry that reversed.

\section{Conclusions}

The horn keratin of bighorn sheep is well-suited for sustaining impacts. Results show that while strength is reduced in the hydrated condition, the large increases in ductility greatly enhance the energy absorbed, or toughness, of the horn. This effect has been reported in literature for quasi-static strain rates but not at higher strain rates as reported herein. This research also revealed that keratin exhibited a pronounced stress increase at higher strain rates (similar to polymers), which further adds to the toughness of the horn during impacts. Some key conclusions from the mechanical testing of horn keratin are summarized below:

- $\quad$ As the applied strain rate that was applied to the Horn keratin increased, the flow stress increased for any stress state and moisture condition.

- $\quad$ As the moisture content increased in the Horn keratin, the ductility increased but the strength decreased.

- $\quad$ The anisotropy of the Horn keratin was evident as the ductility increased in the longitudinal orientation when compared to the radial orientation, and the failure mode changed from lamellar buckling in the longitudinally loaded orientation to shear delamination in the radially loaded orientation.

- $\quad$ The stress state response of the Horn keratin was evident as the tensile failure in the longitudinal orientation occurred by lamellar delamination combined with tubule pullout and fracture, whereas compressive failure occurred by lamellar buckling in the longitudinal orientation and shear delamination in the radial orientation.

\section{Acknowledgments}

Support from the Center for Advanced Vehicular Systems (CAVS) at Mississippi State University is gratefully acknowledged. This work is based upon work supported by the Department of Energy Southern Regional Center for Lightweight Innovative Design (SRCLID), under award number DE-EE0002323. This report was prepared as an account of work sponsored by an agency of the United States Government. Neither the United States Government nor any agency thereof, nor any of their employees, makes any warranty, expressed or implied, or assumes any legal liability or responsibility for the accuracy, completeness, or usefulness of any 
information, apparatus, product, or process disclosed, or represents that its use would not infringe privately owned rights. Reference herein to any specific commercial product, process, or service by trade name, trademark, manufacturer, or otherwise does not necessarily constitute or imply its endorsement, recommendation, or favoring by the United States Government or any agency thereof. The views and opinions of authors expressed herein do not necessarily state or reflect those of the United States Government or any agency thereof.

\section{References}

[1] V. Geist, Mountain Sheep, in: G. Greenberg, M. Haraway (Eds.), Comparative Psychology: A Handbook, Routledge, 1998: pp. 441-443.

[2] J. Hogg, Mating in bighorn sheep: multiple creative male strategies, Science. 225 (1984) 526 -529. doi:10.1126/science.6539948.

[3] A. Kitchener, An analysis of the forces of fighting of the blackbuck (Antilope cervicapra) and the bighorn sheep (Ovis canadensis) and the mechanical design of the horns of bovids, J Zoolog. 214 (1988) 1-20.

[4] McKittrick J, Chen PY, Tombolato L, Novitskaya EE, Trim MW, Hirata GA, Olevsky EA, Horstemeyer MF, Meyers MA, Energy absorbent natural materials and bioinspired design strategies: A review. Mater Sci and Eng: C 2010;30:331.

[5] L. Tombolato, E.E. Novitskaya, P.Y. Chen, F.A. Sheppard, J. McKittrick, Microstructure, elastic properties and deformation mechanisms of horn keratin, Acta Biomaterialia. 6 (2010) 319-330.

[6] A. Kitchener, Fracture toughness of horns and a reinterpretation of the horning behavior of bovids., J Zoolog Lond. 213 (1987) 621-639.

[7] P.-Y. Chen, J. McKittrick, M.A. Meyers, Biological materials: Functional adaptations and bioinspired designs, Progress in Materials Science. 57 (2012) 1492-1704. doi:10.1016/j.pmatsci.2012.03.001.

[8] B. Wang, W. Yang, J. McKittrick, M.A. Meyers, Keratin: Structure, mechanical properties, occurrence in biological organisms, and efforts at bioinspiration, Progress in Materials Science. 76 (2016) 229-318. doi:10.1016/j.pmatsci.2015.06.001.

[9] N. Lee, M.F. Horstemeyer, H. Rhee, B. Nabors, J. Liao, L.N. Williams, Hierarchical multiscale structure-property relationships of the red-bellied woodpecker (Melanerpes carolinus) beak, Journal of The Royal Society Interface. 11 (2014) $20140274-20140274$. doi:10.1098/rsif.2014.0274.

[10] K.R. Makinson, The elastic anisotropy of keratinous solids. I. The dilatational elastic constants, Aust. J. Biol. Sci. 7 (1954) 336-347.

[11] J. McKittrick, P.-Y. Chen, S.G. Bodde, W. Yang, E.E. Novitskaya, M.A. Meyers, The Structure, Functions, and Mechanical Properties of Keratin, JOM. 64 (2012) 449-468. doi:10.1007/s11837-012-0302-8.

[12] M.A. Meyers, A.Y.M. Lin, Y. Seki, P.Y. Chen, B.K. Kad, S. Bodde, Structural biological composites: an overview, JOM Journal of the Minerals, Metals and Materials Society. 58 (2006) 35-41.

[13] S. Lee, E.E. Novitskaya, B. Reynante, J. Vasquez, R. Urbaniak, T. Takahashi, E. Woolley, L. Tombolato, P.Y. Chen, J. McKittrick, Impact testing of structural biological materials, Materials Science and Engineering: C. 31 (2011) 730-739. 
[14] B. Ji, H. Gao, Mechanical properties of nanostructure of biological materials, Journal of the Mechanics and Physics of Solids. 52 (2004) 1963-1990.

[15] M.W. Trim, M.F. Horstemeyer, H. Rhee, H. El Kadiri, L.N. Williams, J. Liao, K.B. Walters, J. McKittrick, S.J. Park, The effects of water and microstructure on the mechanical properties of bighorn sheep (Ovis canadensis) horn keratin, Acta Biomaterialia. 7 (2011) $1228-1240$.

[16] R.H.C. Bonser, Hydration sensitivity of ostrich claw keratin, Journal of Materials Science Letters. 21 (2002) 1563-1564.

[17] A.M. Taylor, R.H.C. Bonser, J.W. Farrent, The influence of hydration on the tensile and compressive properties of avian keratinous tissues, Journal of Materials Science. 39 (2004) 939-942.

[18] B.W. Li, H.P. Zhao, X.Q. Feng, W.W. Guo, S.C. Shan, Experimental study on the mechanical properties of the horn sheaths from cattle, Journal of Experimental Biology. 213 (2010) 479-486.

[19] M. Feughelman, Mechanical properties and structure of alpha-keratin fibres: wool, human hair, and related fibres, UNSW Press, Sydney, 1997.

[20] J.E. Bertram, J.M. Gosline, Functional design of horse hoof keratin: the modulation of mechanical properties through hydration effects, Journal of Experimental Biology. 130 (1987) 121-136.

[21] B. Hopkinson, A Method of Measuring the Pressure Produced in the Detonation of High Explosives or by the Impact of Bullets, Philosophical Transactions of the Royal Society A: Mathematical, Physical and Engineering Sciences. 213 (1914) 437-456. doi:10.1098/rsta.1914.0010.

[22] H. Kolsky, An Investigation of the Mechanical Properties of Materials at very High Rates of Loading, Proceedings of the Physical Society. Section B. 62 (1949) 676-700. doi:10.1088/0370-1301/62/11/302.

[23] A. Kitchener, J. Vincent, Composite theory and the effect of water on the stiffness of horn keratin, J Mater Sci. 22 (1987) 1385-1389.

[24] S.-Y. Fu, B. Lauke, E. Mäder, C.-Y. Yue, X. Hu, Tensile properties of short-glass-fiberand short-carbon-fiber-reinforced polypropylene composites, Composites Part A: Applied Science and Manufacturing. 31 (2000) 1117-1125. doi:10.1016/S1359-835X(00)00068-3.

[25] R.D. Fraser, T.P. Macrae, Molecular structure and mechanical properties of keratins, Symp. Soc. Exp. Biol. 34 (1980) 211-246.

[26] R.D. Fraser, T.P. MacRae, D.A. Parry, E. Suzuki, Intermediate filaments in alpha-keratins, Proc. Natl. Acad. Sci. U.S.A. 83 (1986) 1179-1183.

[27] W.R. Blumenthal, Influence of Temperature and Strain Rate on the Compressive Behavior of PMMA and Polycarbonate Polymers, in: AIP, 2002: pp. 665-668. doi:10.1063/1.1483626. 


\section{List of Tables}

Table 1. Statistical Analysis comparing strength for different orientations with the addition of moisture for high strain rate compressive loading.

\begin{tabular}{c|c|c|c|c} 
& Dry Longitudinal & Wet Longitudinal & Dry Radial & Wet Radial \\
\hline $\begin{array}{c}\text { Average Strength } \\
(\mathrm{MPa})\end{array}$ & 165 & 28 & 109 & 27 \\
\hline $\begin{array}{c}\text { Strength Change } \\
\text { with Moisture (\%) }\end{array}$ & -83 & -75 \\
\hline $\mathrm{t}$ Stat & 7.9 & 10.3 \\
\hline $\mathrm{t}$ Critical & 1.8 & 2.1 \\
\hline $\mathrm{P}\left(\mathrm{t}_{\text {stat }} \leq \mathrm{t}_{\text {crit }}\right)$ & $7 \times 10^{-6}$ & $5 \times 10^{-4}$
\end{tabular}

Table 2. Statistical Analysis comparing strength for different orientations with the addition of moisture for high strain rate tensile loading.

\begin{tabular}{c|c|c|c|c} 
& Dry Longitudinal & Wet Longitudinal & Dry Radial & Wet Radial \\
\hline $\begin{array}{c}\text { Average Strength } \\
(\mathrm{MPa})\end{array}$ & 117 & 49 & 48 & 34 \\
\hline $\begin{array}{c}\text { Strength Change } \\
\text { with Moisture }(\%)\end{array}$ & -58 & -29 \\
\hline $\mathrm{t}$ Stat & 5.2 & 4.97 \\
\hline $\mathrm{t}$ Critical & 4.3 & 2.45 \\
\hline $\mathrm{P}\left(\mathrm{t}_{\text {stat }} \leq \mathrm{t}_{\text {crit }}\right)$ & 0.03 & 0.003
\end{tabular}

\section{List of Figures}


Figure 1. Schematics showin (a) orientation of compressive and tensile test specimens, and (b) hierarchical structure of the horn at different length scales. Reprinted from [5], with permission from Elsevier.

Figure 2. High rate compression stress-strain results demonstrating the effects of moisture and anisotropy. Increased moisture increased the ductility, decreased the strength, and decreased the effect of anisotropy. Each curve consists of at least three tests. Error bars denote standard deviation values.

Figure 3. High rate tension stress-strain results demonstrate the effects of moisture and anisotropy. The longitudinal orientation possessed greater strength in the dry condition but more ductility in the wet condition compared to the radial orientation. Each curve consists of at least three tests. Error bars denote standard deviation values.

Figure 4. Scanning Electron Microscope (SEM) images showing (a) the fracture surface of dry longitudinal high rate tension specimen delineating brittle failure and delamination and (b) the fracture surface with tubules identified in the circles.

Figure 5. Scanning Electron Microscope (SEM) images of (a) the fracture surface of a wet longitudinal high rate specimen, (b) the zoomed in fractured tubule fibers and (c) the keratin matrix showing ductile failure. Although not shown here the fiber pullout and matrix ductility were greater for the wet specimen when compared to the dry specimen.

Figure 6. Scanning Electron Microscope (SEM) images showing the fracture surface of a dry radial high rate tension specimen showing (a) brittle failure and tubule debonding circled in white. (b) Image showing the tubule zoomed in.

Figure 7. Scanning Electron Microscope (SEM) images showing (a) the fracture surface of a wet radial high rate tension specimen with delaminated tubule region highlighted in white and (b) a zoomed in region of the delaminated tubule.

Figure 8. Stress-strain test results from the longitudinal dry condition over different stress states and strain rates. Note the increase in stress caused by higher strain rates for both tension and compression. Positive and negative strain rates represent tension and compression, respectively. 
Each curve consists of at least three tests. Error bars denote standard deviation values. Quasistatic data taken from Trim et al. [15].

Figure 9. Stress-strain test results from the longitudinal wet condition over different stress states and strain rates. High rate tensile loading caused the greatest increase in stress. Positive and negative strain rates represent tension and compression, respectively. Each curve consists of at least three tests. Error bars denote standard deviation values. Quasi-static data taken from Trim et al. [15].

Figure 10. Stress-strain test results from the radial dry condition over different stress states and strain rates. The strain rate dependence is minor in the radial dry condition. Positive and negative strain rates represent tension and compression, respectively. Each curve consists of at least three tests. Error bars denote standard deviation values. Quasi-static data taken from Trim et al. [15].

Figure 11. Stress-strain test results from the radial wet condition over different stress states and strain rates. Although high strain rates increased the stress response, strain to failure was decreased. Positive and negative strain rates represent tension and compression, respectively. Each curve consists of at least three tests. Error bars denote standard deviation values. Quasistatic data taken from Trim et al. [15].

Figure 12. High rate results from the longitudinal orientation in different stress states and moisture contents. The addition of moisture produced a stress state asymmetry reversal. Compression caused the highest yield strength in dry conditions, while tension caused the highest yield strength in wet conditions. Each curve consists of at least three tests. Error bars denote standard deviation values. 

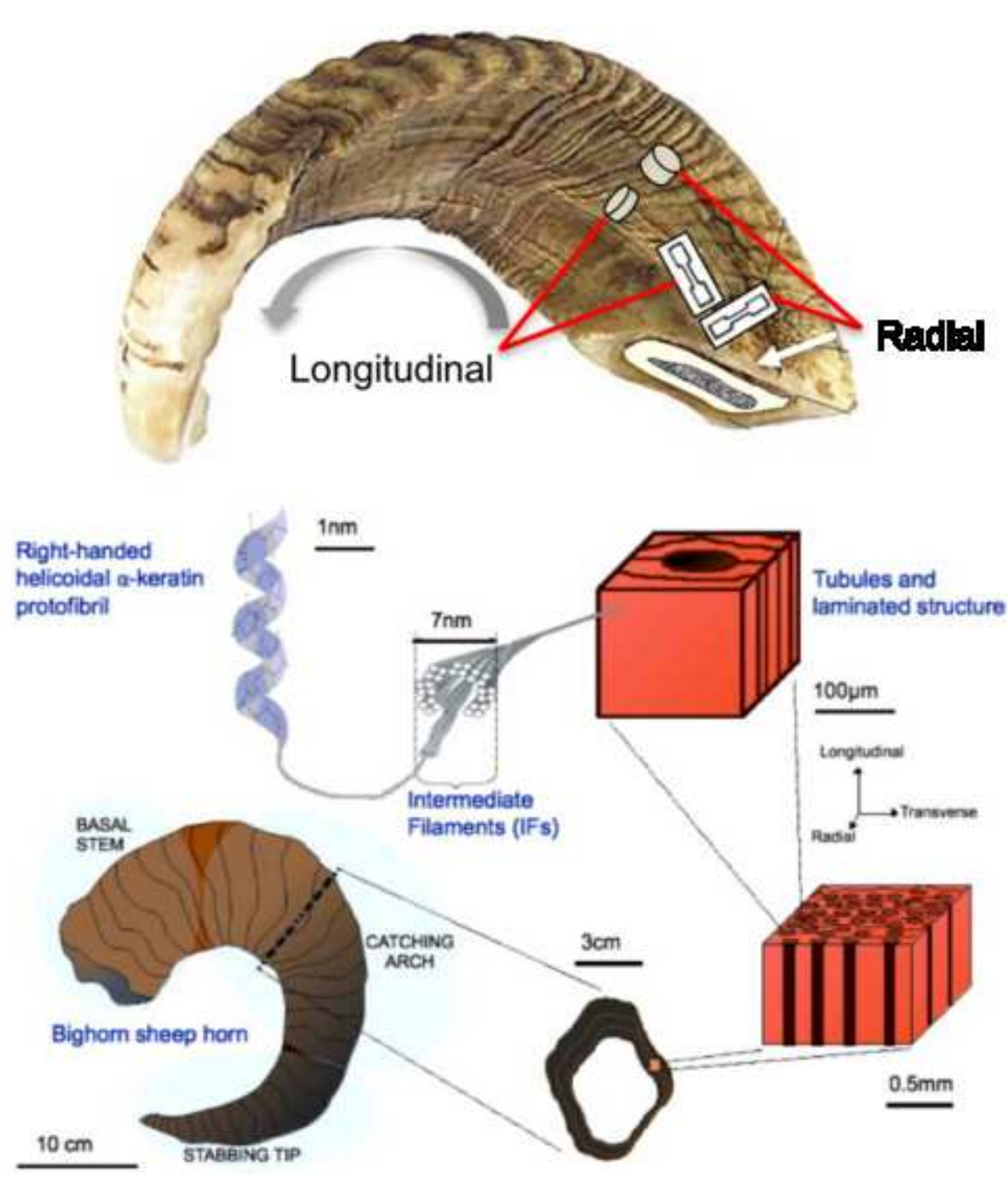

\section{Longitudinal}

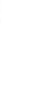




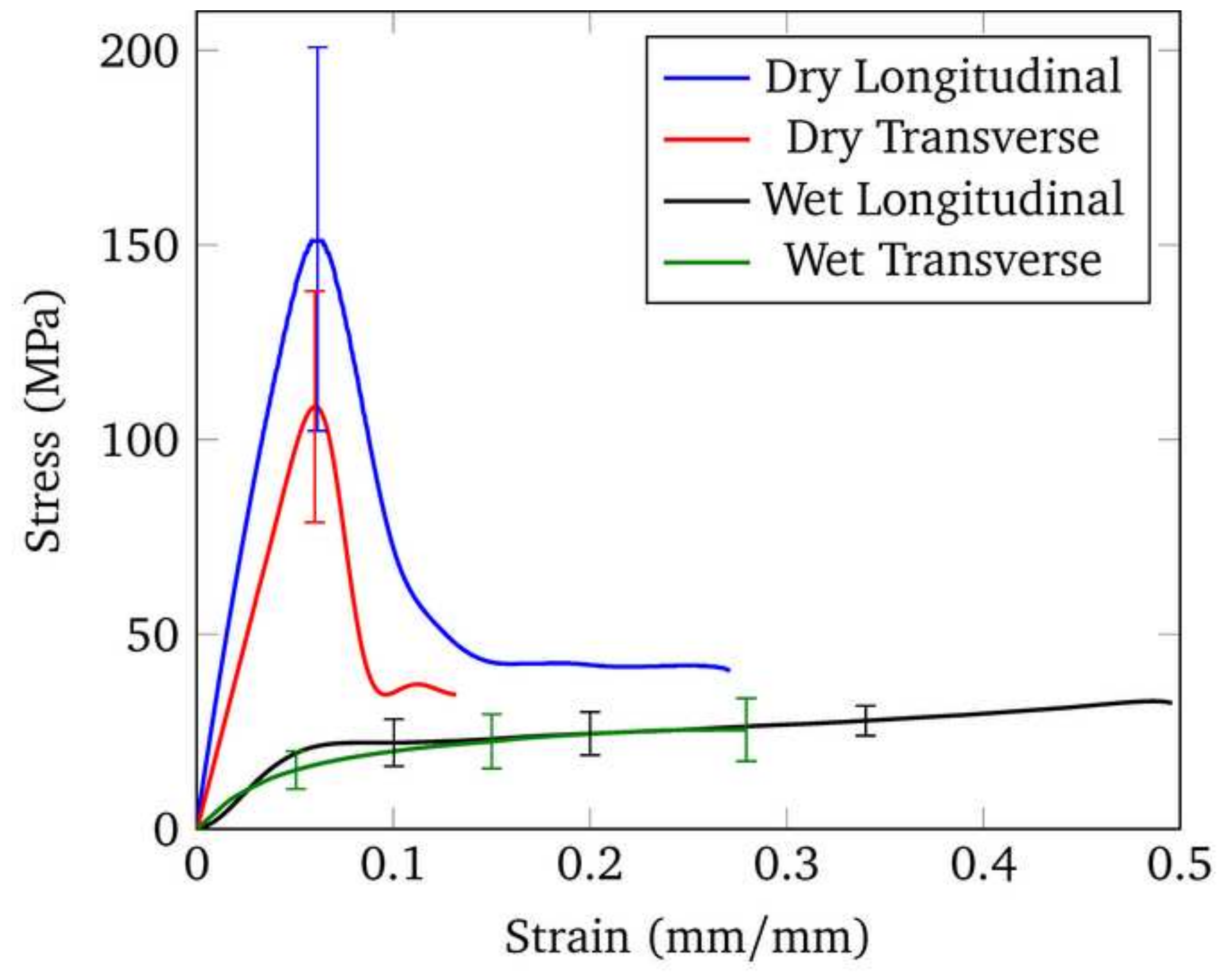




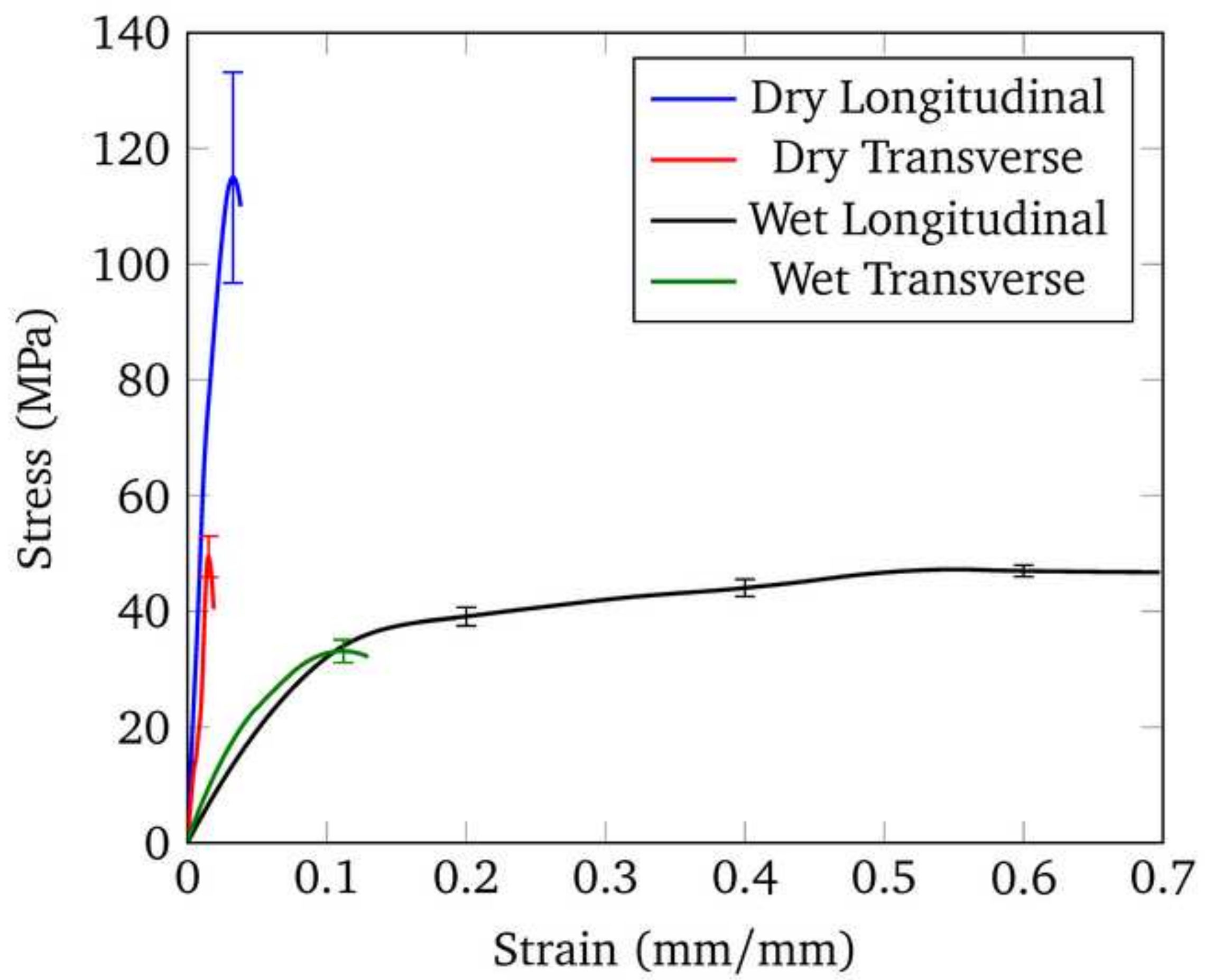



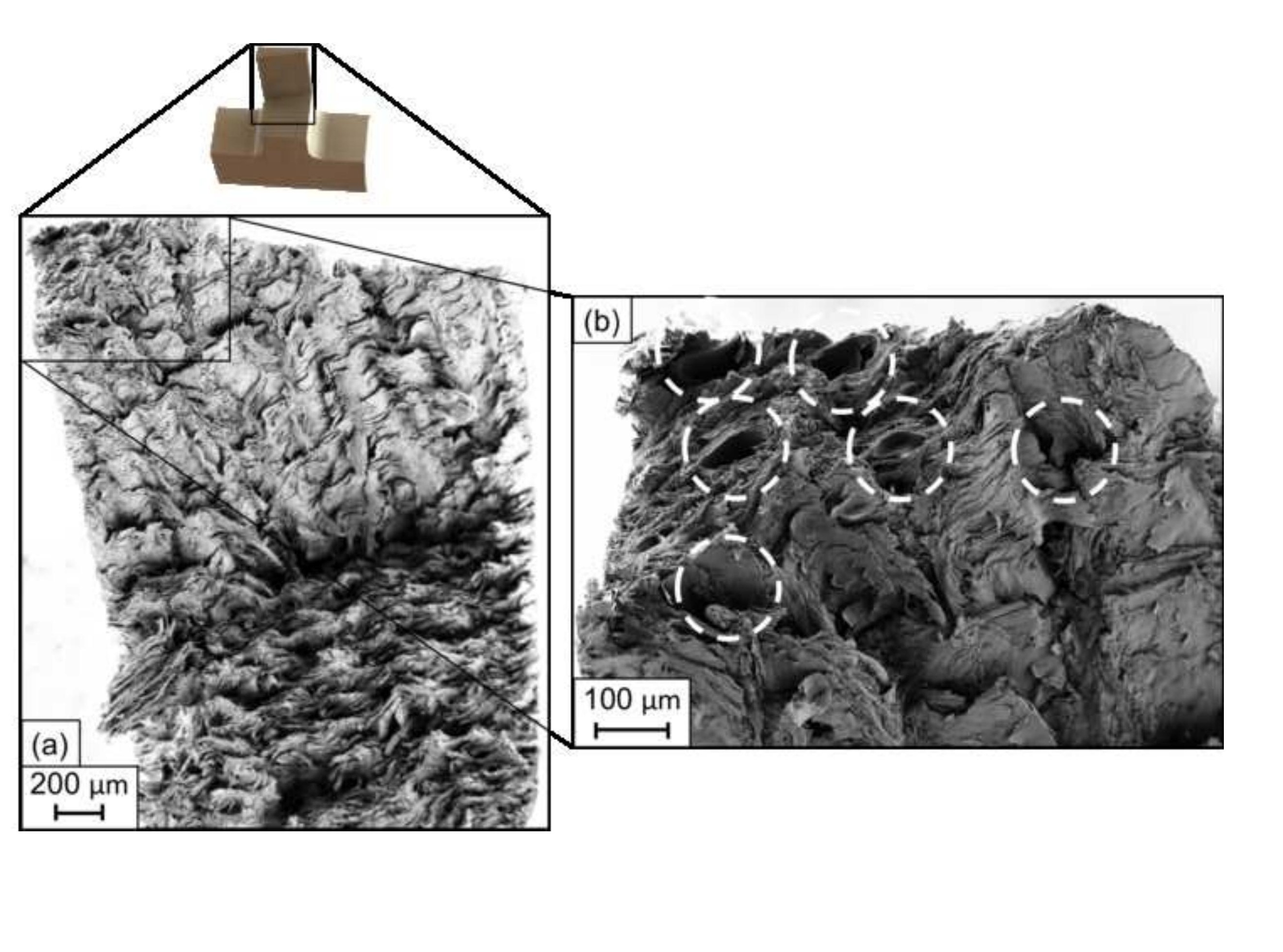


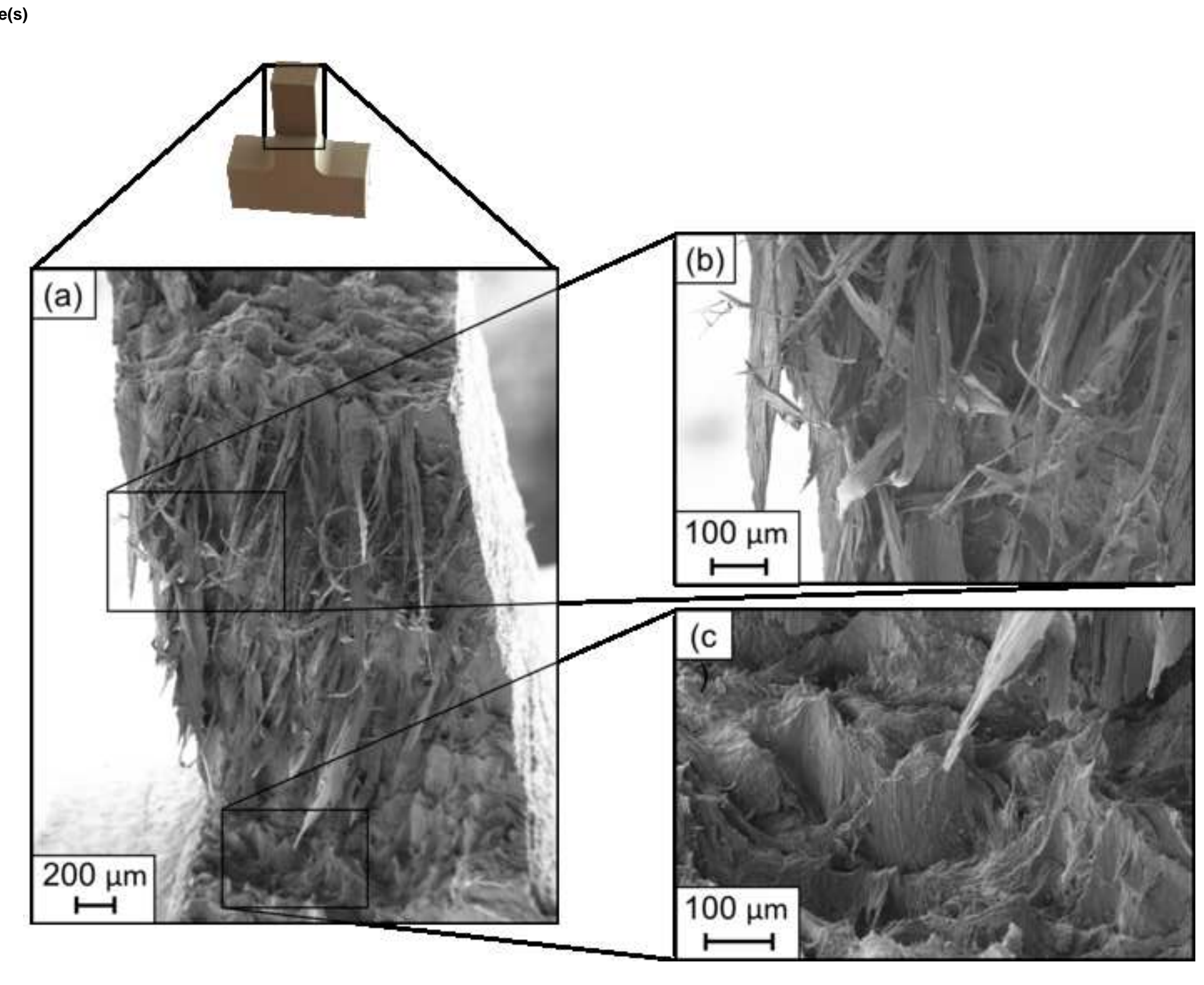




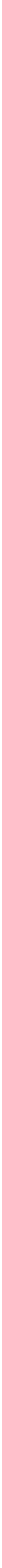

.

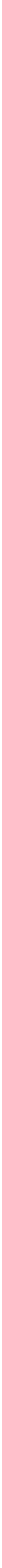

. 


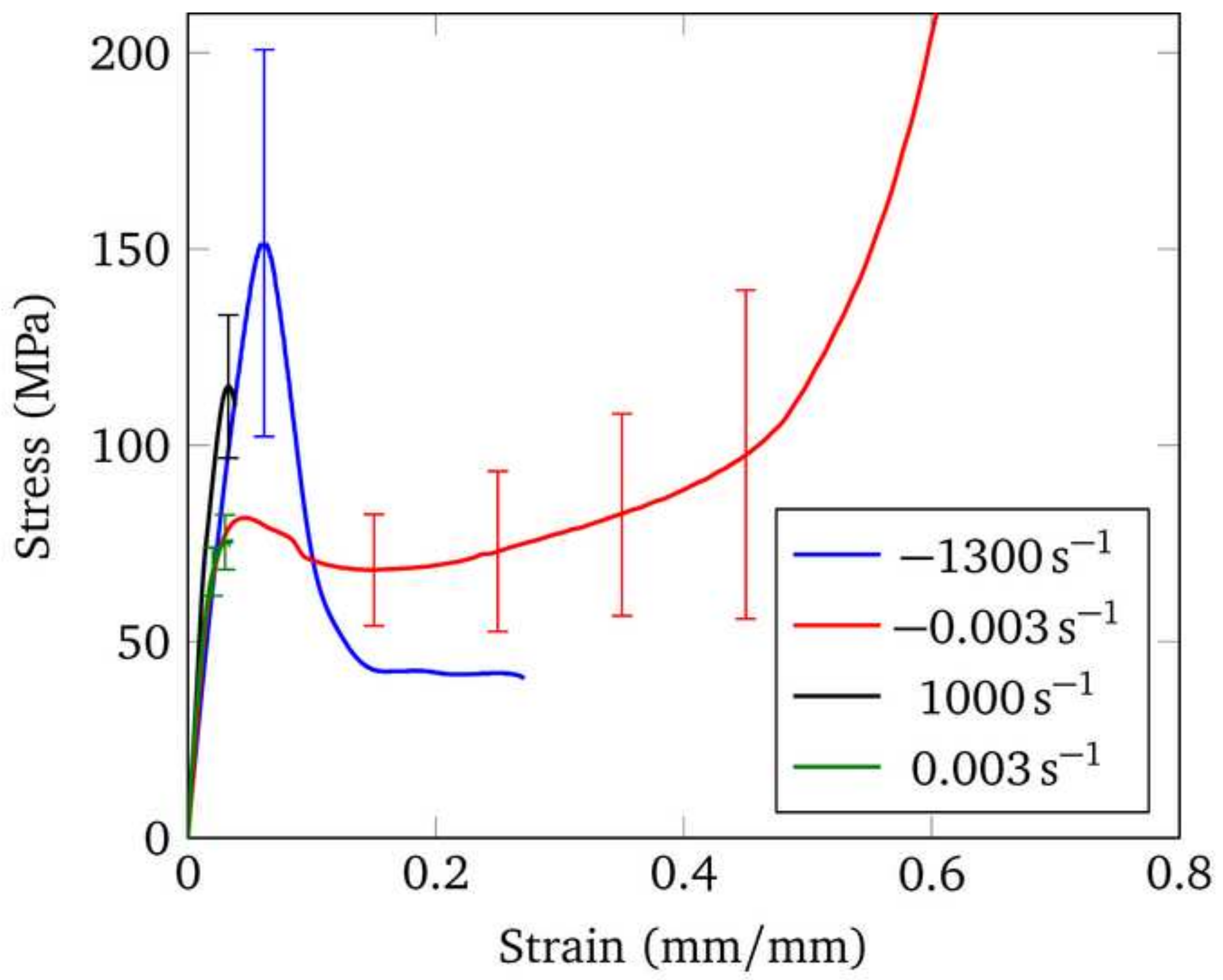




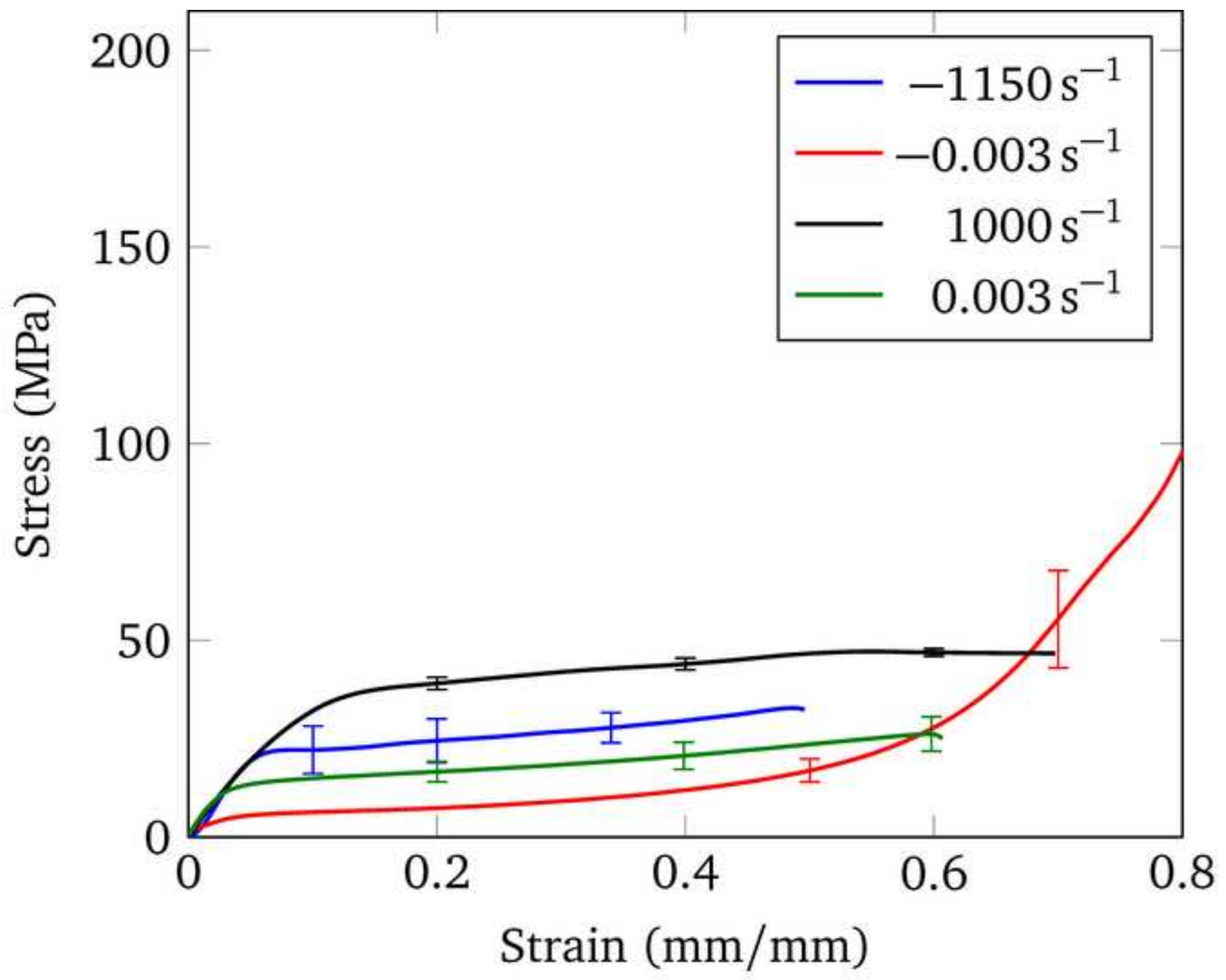




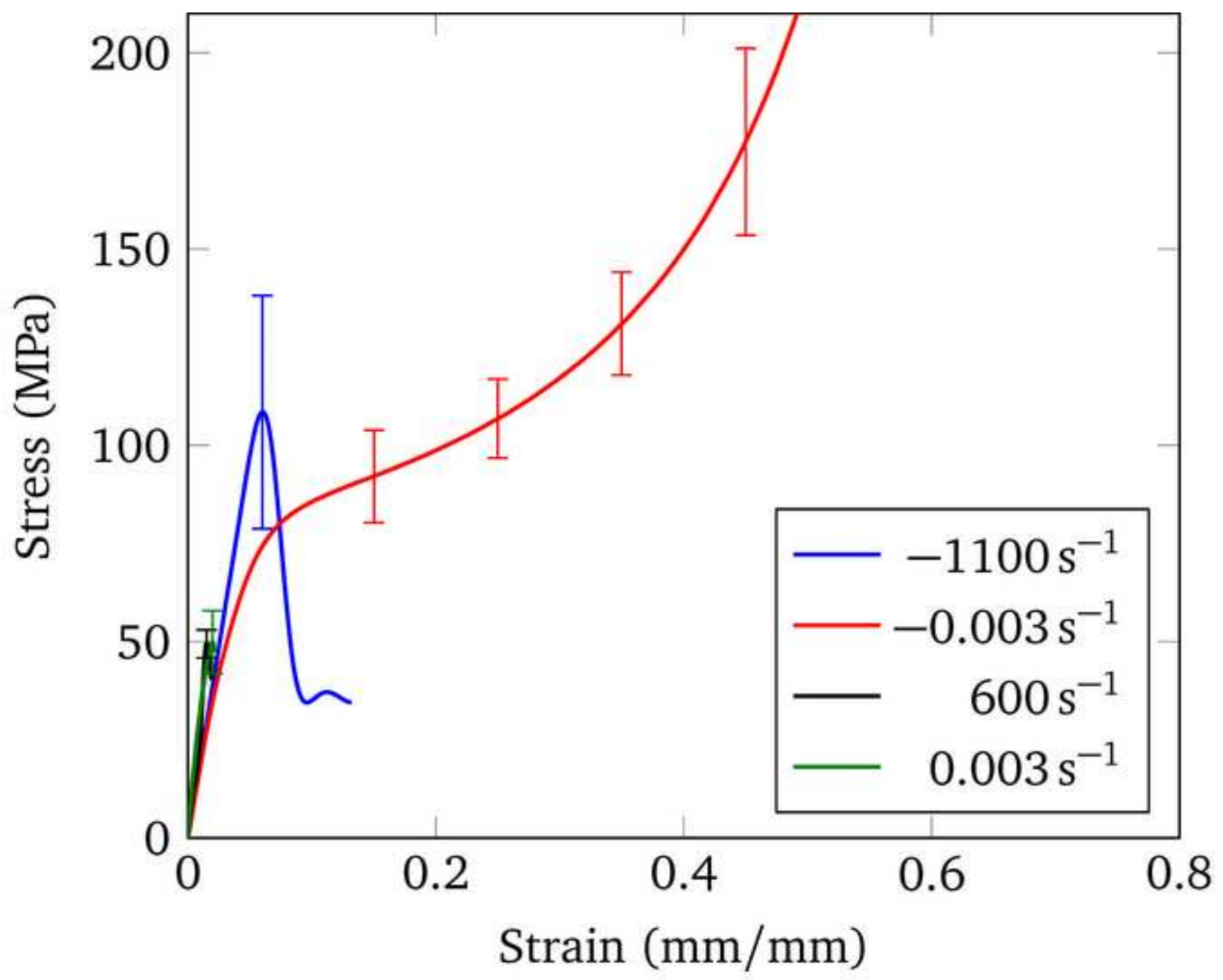




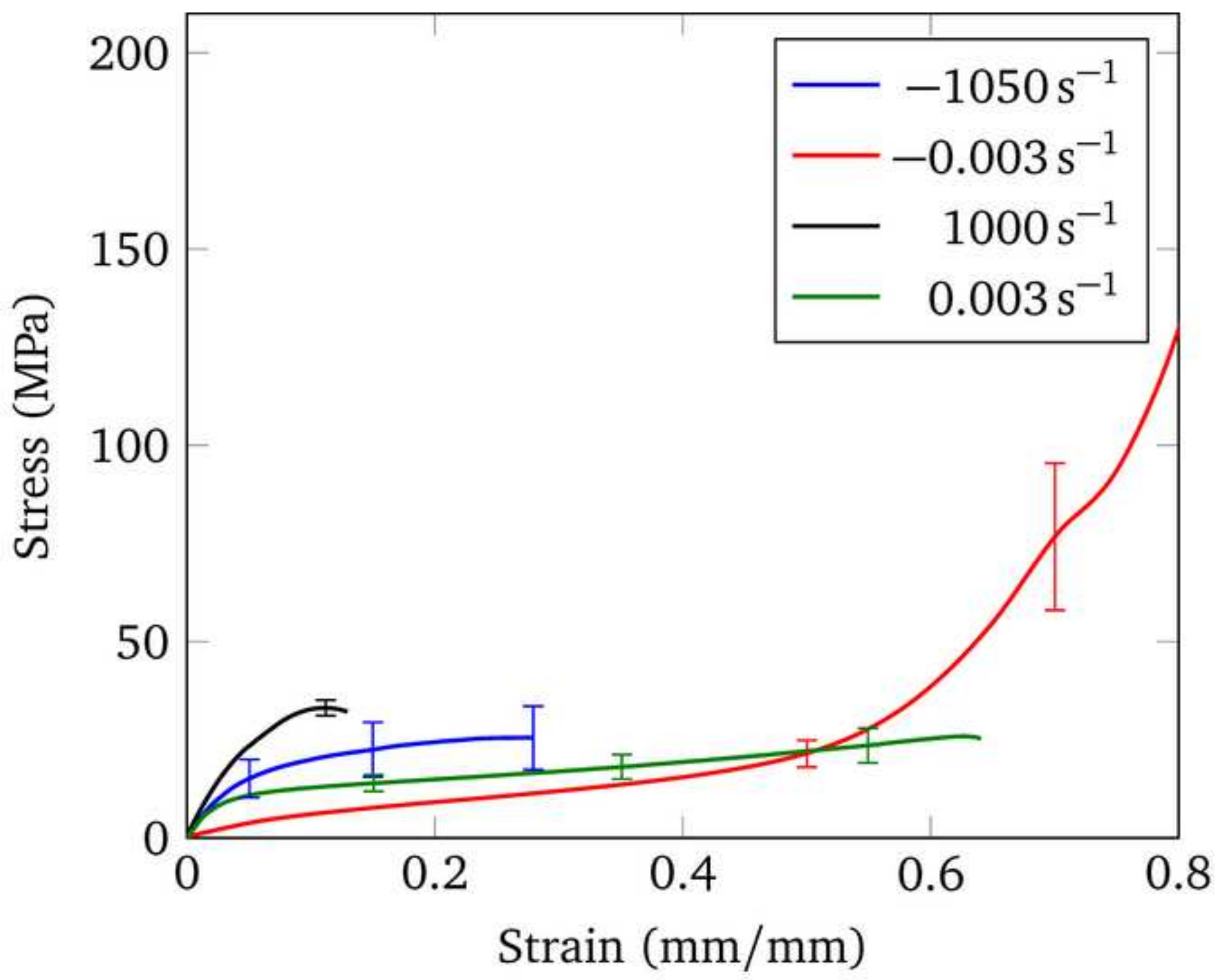




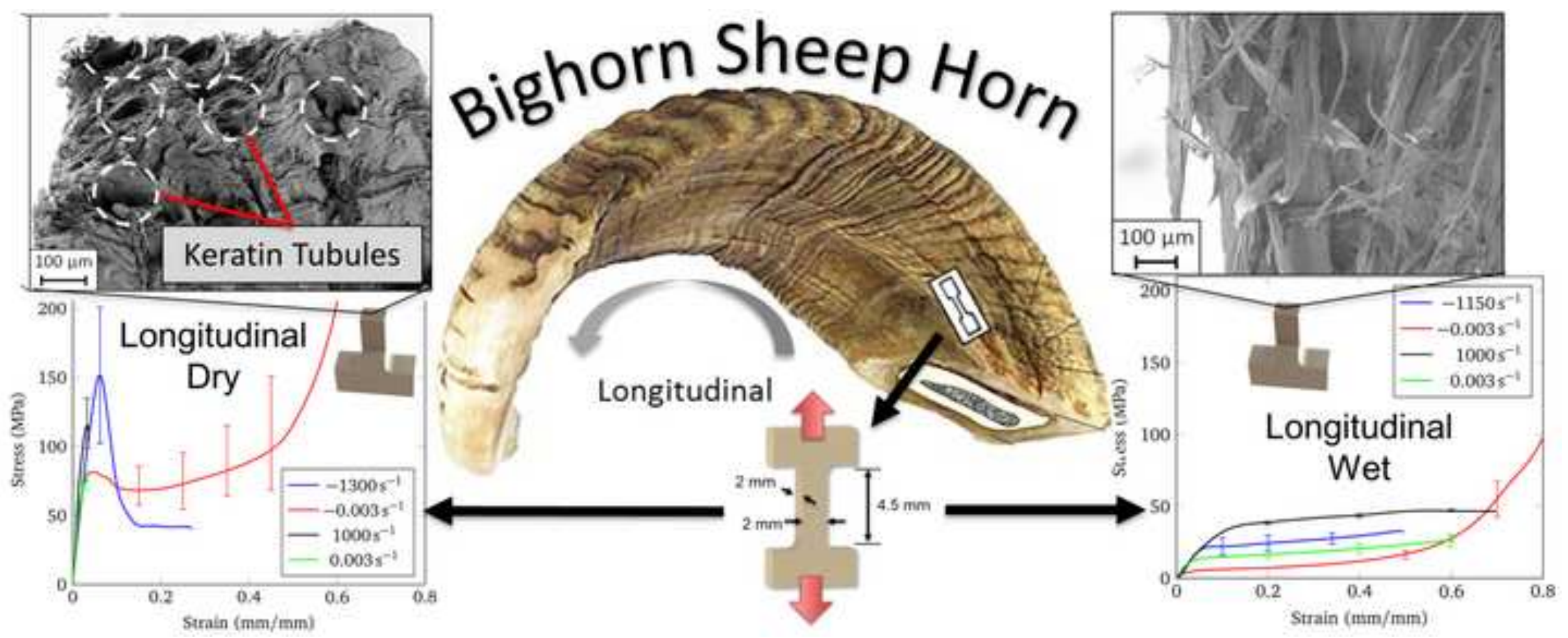

